\title{
Bölgesel Çeşitlilik mi Uzmanlaşma mı? İllerin İmalat Sanayinde Çeşitlilik/Uzmanlaşma Düzeylerine Göre Siralanmasi
}

\author{
Onur Sungur ${ }^{1}$ \\ ORCID: 0000-0001-6778-4370
}

\author{
Habibe Yaman ${ }^{2}$ \\ ORCID: 0000-0002-9212-3264
}

Öz

Bölgelerin inovasyon-büyüme süreçlerindeki farklllklar ve bölgesel çeşitlenmenin/uzmanlaşmanin ardinda yatan nedenlerin incelenmesi, son zamanlarda bilim insanlar ve politika belirleyicilerinin gündemindedir. Bu konuda Bölge Bilimi literatüründe son yillarda giderek artan ilgi oluşturan iki önemli ana kavram bulunmaktadır. Bunlar "bölgesel uzmanlaşma" ve "bölgesel çeşitlilik" kavramlardır. Her iki kavram da bölgelerin veya bölgede yer alan firmalarm yenilikçilik, rekabet, büyüme performansı veya bölgelerin krizlere-resesyonlara karşı koyabilme yeteneği konusunda çeşitli çıkarımlarda bulunmaktadır. Bu çalışmanın amaci; Türkiye'de illerin imalat sanayi sektöründe çeşitlilik/uzmanlaşma düzeylerinin tespit edilmesidir. Bu kapsamda; iller itibariyle 2019 yll istihdam verilerinden yararlanularak illerin göreli çeşitlilik/yoğunlaşma endeksi (Duranton-Puga Endeksi) hesaplanmaktadır. Sektörel çeşitlilik/uzmanlaşma değerleri kullanılarak illerin sıralaması yapılmaktadır. Analiz sonucuna göre, 81 il için Duranton-Puga Endeksi 0,58 ile 3,76 arasında deği̧skenlik göstermektedir. İmalat sanayi sektöründe İzmir, İstanbul, Adana, Samsun, Tekirdağ gibi illerde endeks değerinin yüksek olduğu ve bu illerde istihdamın farklı sanayi kollarına dă̆ıldığı yoğunlaşmanın az olduğu saptanmıştır. Endeks değerinde son siralarda yer alan Hakkâri, Artvin, Siirt, Bitlis, Bayburt gibi illerde ise istihdamın çok fazla sektörde çeşitlenmediği belli sektörlerde yoğunlaştığı bulunmuş̧tur.

Anahtar Kelimeler: Bölgesel Uzmanlaşma, Bölgesel Çeşitlilik, İmalat Sanayi, Duranton-Puga Endeksi.

\footnotetext{
${ }^{1}$ Doç. Dr., Burdur Mehmet Akif Ersoy Üniversitesi, E-mail: onursungur@mehmetakif.edu.tr 2 Öğr. Gör., Burdur Mehmet Akif Ersoy Üniversitesi, E-mail: hyaman@mehmetakif.edu.tr id ealkent (c) Kent Araştırmaları Dergisi (Journal of Urban Studies) 


\title{
Regional Diversity or Specialization? Ranking of Provinces According to Diversity/Specialization Levels in Manufacturing Industry
}

\author{
Onur Sungur ${ }^{3}$ \\ ORCID: 0000-0001-6778-4370
}

\author{
Habibe Yaman ${ }^{4}$ \\ ORCID: 0000-0002-9212-3264
}

\begin{abstract}
Differences in regions' innovation-growth processes and the reasons behind regional diversification/specialization have recently been on the agenda of scientists and policy makers. In this regard, there are two major concepts in the Regional Science literature that have gained increasing interest in recent years. These are "regional specialization" and "regional diversification". Both concepts have various implications for innovativeness, competition, growth performance or the ability of regions to respond to crises-recessions. The purpose of this study is to determine the variety/specialization level of provinces in manufacturing industry in Turkey. Relative diversity/concentration index (Duranton-Puga Index) is calculated by using the employment data by provinces by the year of 2019. Then, by using sectoral diversity/specialization value of the provinces, provinces are ranked in the manufacturing sector. As a result of the analysis, the Duranton-Puga Index varies between 0.58 and 3.76 for 81 provinces. Index value is high in provinces such as Izmir, Istanbul, Adana, Samsun and Tekirdağ, and the concentration in these provinces is distributed to different industries. In provinces such as Hakkâri, Artvin, Siirt, Bitlis and Bayburt, it is found that employment is concentrated in certain sectors where there is not much diversification.
\end{abstract}

Keywords: Regional Specialization, Regional Diversification, Manufacturing Industry, DurantonPuga Index.

\footnotetext{
${ }^{3}$ Assoc. Prof., Burdur Mehmet Akif Ersoy University, E-mail: onursungur@mehmetakif.edu.tr ${ }^{4}$ Lecturer, Burdur Mehmet Akif Ersoy University, E-mail: hyaman@mehmetakif.edu.tr id ealkent (c) Kent Araştırmaları Dergisi (Journal of Urban Studies) http://idealkentdergisi.com

Geliş Tarihi Received Date: 21.12.2020 Kabul Tarihi Accepted Date: 28.04.2021
} 


\section{Giriş: Bölgesel Çeşitlilik ve Uzmanlaşma}

1980'li yıllarda yüksek işsizlik ve yavaş büyümenin yarattı̆̆ mevcut ekonomik koşullar, yerel ekonomik kalkınmanın sistematik planlanmasına yönelik yoğun çaba sarf edilmesini gerektirmiştir (bkz. Ledebur, 1983'ten aktaran Jackson, 1984, s. 103; Pascal ve Gurwitz, 1983; Wolman 1979). Yaklaşık 40 yıldır bölgesel iktisat literatüründe, bölgesel istihdamın sektörel yapısı/dağılımı ve bölgesel ekonomik büyüme ve istikrar arasındaki ilişkiye odaklanılmaktadır.

Bölgelerin inovasyon-büyüme süreçlerindeki farklılıklar ve bölgesel çeşitlenmenin/uzmanlaşmanın ardında yatan nedenlerin incelenmesi, son zamanlarda bilim insanları ve politika belirleyicilerinin gündemindedir. Ekonomik coğrafya/bölge bilimi/bölgesel iktisat/bölgesel kalkınma alanında son yıllarda yapılan çalışmalarda; bölgelerin yeni endüstriler veya yeni teknolojiler konusunda nasıl çeşitlilik gösterdiği, bölgelerin nasıl yeni büyüme yörüngeleri oluşturduğu, bölgelerin bunu yapabilme yetenekleri konusunda neden farklılaştığ soruları oldukça yoğun bir tartışma konusunu oluşturmaktadır (Boschma ve Frenken, 2006; Boschma vd., 2016). Konuyla ilgili yapılmış pek çok çalışmada; "patika bağımlılığı", "kilitlenme”, "bölgesel esneklik", "bölgesel dayanıklılık”, "bölgesel çeşitlilik", "bölgesel uzmanlaşma”, "bölgesel dallanma” gibi farklı kavramlar ele alınmaktadır (Kavramlara ilişkin bazı çalışmalar için bkz. Binz vd., 2016; Boschma ve Capone, 2015; Boschma ve Frenken, 2011; Boschma vd., 2014; Boschma vd., 2015; Castaldi vd., 2015; Crespo ve Vicente, 2014; Essleztbichler, 2015; Frenken vd., 2007; Hassink, 2005; Martin, 2010; Neffke vd., 2011; Neffke vd., 2014; Rigby, 2015; Simmie, 2012; Tanner, 2014; 2016). Söz konusu kavramlar arasında son yıllarda giderek artan ilgi oluşturan iki önemli ana kavram bulunmaktadır. Bunlardan birisi “bölgesel uzmanlaşma” (regional specialization) iken bir diğeri de "bölgesel çeşitlilik" (regional diversification) kavramıdır. Her iki kavrama ilişkin tartışmalarda bölgelerin veya bölgede yer alan firmaların yenilikçilik, rekabet, büyüme performansı veya bölgelerin krizlere-resesyonlara karşı koyabilme yeteneği konusunda çeşitli çıarımlarda bulunulmaktadır. Bu çıkarımlarda bölgesel çeşitliliğin bölgeyle ilişkili ya da ilişkisiz olabileceğinden bahsedilmektedir. Buna ek olarak büyüme ve gelişme açısından sektörel çeşitliliğin de önemine vurgu yapılmaktadır. Çünkü yeni sektörlerin gelişimi sektörde çeşitliliği sağlarken sektörde çeşitliliğin bulunmaması yani sektörel çeşitsizliğin olması üretim esnekliğini kısıtlamakta, büyüme ve gelişme düzeyine de etki etmektedir. Fakat bu durum sadece ülke ve bölgeler için değil aynı zamanda iller için de geçerlidir. 
İlin sektörel uzmanlaşma veya çeşitlilik düzeyi, ilin dış ticaret performansını ve ulusal/küresel ekonomik şoklara karşı dayanıklılı̆̆ını etkilemektedir. Örneğin; ilin sektörel çeşitliliğinin düşük olması durumunda, ihracattan alınan payın yüksek olduğu sektörlerde yaşanacak bir talep düşüşünün ilin ekonomisinin olumsuz etkilemesi muhtemeldir. İhracatının büyük bir kısmını birkaç sektörden karşılayan bir ilin, bu sektörlerde yaşanacak olumsuz küresel gelişmeler karşısında üretim, istihdam ve ihracat düşüşü yaşama ihtimali oldukça yüksektir. Bu bakımdan sadece ihracat açısından değil, bir bütün olarak ilin ekonomisinin istikrarlı büyüyebilmesi için sektörel çeşitlilik önem arz etmektedir (TEPAV, 2016, s.44). Conroy (1972'den aktaran Jackson, 1984, s.104), bölgesel çeşitliliğin istikrar sağlayıc özelliğine vurgu yapmakta ve "toplam bölgesel ekonomik faaliyette beklenen dalgalanmalarm azaltılması temelinde çeşitlendirmenin, bölgesel istikrarm bir bütün olarak ülkeninkinden çok daha fazla olmasına yol açabileceğini" belirtmektedir. Dolayısıyla, sektörel çeşitliliğin az olmasından kaynaklanabilecek bu tür risklerin azaltılabilmesi açısından, sektörel çeşitliliği az olan illerin/bölgelerin, sektörel çeşitlenme politikaları uygulaması gerekmektedir. Buna ek olarak sektörel çeşitlilik, yeni sektörlerin gelişme potansiyelini de arttırmaktadır. Sektörel çeşitlilik ile yeni sektörel gelişme arasında pozitif bir ilişki bulunmaktadır. Yeni sektörlerin gelişebilmesi ve üretimin çeşitlenebilmesi için, farklı sektörlerde kullanılan birbirinden farklı üretim becerilerinin bir araya getirilmesi gerekmektedir. Tek veya birkaç sektörün hâkim olduğu bir ilde (veya bölgede), mevcut bilgi-beceri zenginliğinin de düşük olması nedeniyle, yeni sektörlerin gelişmesi de mümkün olmayacaktır. Bir bakıma sektörel çeşitsizlik, becerilerdeki çeşitsizlik olarak da yorumlanmaktadır (TEPAV, 2016, s.44).

Bununla birlikte, bir yandan sektörel çeşitlilik kavramı bölgesel ekonomik istikrar sağlanması açısından önem arz ederken diğer taraftan sektörel uzmanlaşmanın küresel rekabet gücü kazanılması açısından önemi pek çok çalışmada vurgulanmaktadır (Aiginger ve Rossi-Hansberg, 2006; Ezcurra vd., 2006; Marelli, 2006). Bölgesel uzmanlaşma ve endüstriyel yoğunlaşmaya odaklanan modeller ve ampirik çalışmaların temelleri esas olarak 19-20. yüzyıl ticaret teorisi ve Yer Seçimi (Lokasyon) Kuramına dayanmaktadır. Bölgesel uzmanlaşma; ülkenin geri kalanına kıyasla bölgenin genel ekonomisi içerisindeki sektörel payların dağılımını göstermektedir. Az sayıda endüstrinin, o bölgenin ekonomisinde büyük bir birleşik paya sahip olması, bölgenin oldukça uzmanlaşmış olduğu anlamina gelmektedir (Goschin vd., 2009, s.100). TEPAV (2016, s.44) tarafından yapılan bir çalışmada, illerin sektörel çeşitlenme ihtiyaçlarının, illerin 
gelişmişlik düzeylerine göre farklılaştığı belirtilmekte ve belli bir gelişmişlik seviyesini aşan iller için sektörel çeşitlilikten ziyade sektörel uzmanlaşmanın uygun olacağı düşünülmektedir.

Bu çalışmanın amacl; Türkiye'de illerin imalat sanayi sektöründe çeşitlilik/uzmanlaşma düzeylerinin tespit edilmesidir. Bu kapsamda; iller itibariyle 2019 yılı istihdam verilerinden yararlanılarak illerin göreli çeşitlilik/yoğunlaşma endeksi (Duranton-Puga Endeksi) hesaplanmaktadır. Sektörel çeşitlilik/uzmanlaşma değerleri kullanılarak Türkiye'de imalat sanayi sektörlerine göre illerin sıralaması oluşturulmaktadır. Çalışma sayesinde, Türkiye için illerin çeşitlilik ve uzmanlaşma durumunun ortaya koyulması ve literatüre katkı sağlanması öngörülmektedir.

\section{Literatür Taramas1}

Küreselleşen ekonomi süreciyle beraber bölgeler ve iller arasındaki farklılıklar giderek artmaktadır. Ekonomik kalkınma açısından göz ardı edilemeyecek bu unsur bilgiye dayalı sürecin de etkisiyle çeşitlilik, uzmanlaşma ve yoğunlaşma gibi konuları ön plana çıarmaktadır. İnovasyon, verimlilik, teknoloji vb. pek çok açıdan çeşitlilik, uzmanlaşma ve yoğunlaşmanın bölgesel ve kentsel ekonomik büyüme ve gelişme üzerinde önemli bir etkisi olduğu yazında sıklıkla dile getirilmektedir. Literatürde bölgesel çeşitlilik ve uzmanlaşmayı konu alan pek çok çalışma mevcut olup bu araştırmalarda farklı alanlar ve konu başlıkları ele alınmaktadır. Bu kapsamda konuyu içeren çalışmalar Tablo 1'de özetlenmektedir.

Tablo 1. Literatür Taraması (Yazarlar tarafından oluşturulmuştur).

\begin{tabular}{|c|c|c|c|c|}
\hline Yazar/Y1l & İlgili Konu & Yöntem & Dönem & Sonuç \\
\hline $\begin{array}{l}\text { Askarany ve } \\
\text { Spraakman } \\
(2020)\end{array}$ & $\begin{array}{l}\text { Bölgesel } \\
\text { Çeşitlendirme }\end{array}$ & $\begin{array}{l}\text { Durum } \\
\text { Çalışması }\end{array}$ & 1997-2017 & $\begin{array}{l}\text { Yeni ürünlerin katkı marjı feda } \\
\text { edilenlerden daha yüksekse (dü- } \\
\text { şükse), çeşitlendirmenin daha } \\
\text { yüksek (düşük) finansal perfor- } \\
\text { mansa yol açacağı, böylece firma- } \\
\text { ların çeşitlendirme ve finansal } \\
\text { performansları arasında pozitif } \\
\text { (negatif) bir ilişki görüleceği, eşit } \\
\text { olduğu durumda değişiklik ol- } \\
\text { mayacağı belirtilmektedir. }\end{array}$ \\
\hline $\begin{array}{l}\text { Tsai, Ren ve } \\
\text { Eisingerich } \\
(2020)\end{array}$ & $\begin{array}{l}\text { Bölgesel } \\
\text { Çeşitlendirme }\end{array}$ & $\begin{array}{l}\text { Panel Regresyon } \\
\text { Tahminleri }\end{array}$ & 2005-2014 & $\begin{array}{l}\text { Bölgesel çeşitliliğin firma perfor- } \\
\text { mansı üzerinde önemli bir etkisi } \\
\text { bulunmaktadır. }\end{array}$ \\
\hline $\begin{array}{l}\text { Çiftçi } \\
(2018)\end{array}$ & Uzmanlaşma & $\begin{array}{l}\text { Yerelleşme } \\
\text { Katsayısı } \\
\text { Tekniği (LQ) }\end{array}$ & 2016 yilı & $\begin{array}{l}\text { Akademik pozisyonlara göre } \\
\text { farklı olmakla birlikte bölgesel } \\
\text { uzmanlaşma bağlammnda bölge- } \\
\text { sel dengesizliklerin olduğu be- } \\
\text { lirtilmektedir. }\end{array}$ \\
\hline
\end{tabular}




\begin{tabular}{llllll}
\hline $\begin{array}{l}\text { Şahin, Yılmaz } \\
\text { ve Varol }\end{array}$ & Uzmanlaşma & $\begin{array}{l}\text { Yerelleşme } \\
\text { Katsayısı }\end{array}$ & $\begin{array}{l}2009 \\
2015\end{array}$ & ve & $\begin{array}{l}\text { Tüm bilgi yoğun iş hizmetleri } \\
\text { sektörlerinin (telekomünikas- } \\
\text { (2018) }\end{array}$ \\
& Tekniği (LQ) & yılları & $\begin{array}{l}\text { yon sektörü hariç) uzmanlaşma } \\
\text { alanlarının büyük şehirler ol- } \\
\text { duğu belirtilmektedir. }\end{array}$
\end{tabular}

\begin{tabular}{|c|c|c|c|c|}
\hline $\begin{array}{l}\text { Broekel } \\
\text { ve Mewes } \\
(2017)\end{array}$ & $\begin{array}{l}\text { Bölgesel } \\
\text { Çeşitlendirme }\end{array}$ & $\begin{array}{l}\text { Panel Veri } \\
\text { Analizi }\end{array}$ & $1996-2010$ & $\begin{array}{l}\text { Almanya'daki Ar-Ge politikası- } \\
\text { nın bölgesel teknolojik çeşitliliği } \\
\text { desteklemediği ve etkilemediği } \\
\text { saptanmıştır. }\end{array}$ \\
\hline $\begin{array}{l}\text { Gömleksiz ve } \\
\text { Mercan } \\
\text { (2017) }\end{array}$ & Uzmanlaşma & $\begin{array}{l}\text { Panel Veri } \\
\text { Analizi }\end{array}$ & $2006-2014$ & $\begin{array}{l}\text { Bölgesel ekonomik büyüme } \\
\text { üzerinde, uzmanlaşma ve en- } \\
\text { düstriyel yoğunlaşmaya ilişkin } \\
\text { dişsallıklar önemli belirleyiciler- } \\
\text { dir. }\end{array}$ \\
\hline $\begin{array}{l}\text { Şahin ve } \\
\text { Altuğ } \\
\text { (2017) }\end{array}$ & Uzmanlaşma & $\begin{array}{l}\text { Yenilikçi } \\
\text { Uzmanlaşma } \\
\text { Katsayısı (YUK) }\end{array}$ & $\begin{array}{ll}2007 & \text { ve } \\
2016 & \\
\text { y1lları } & \\
\end{array}$ & $\begin{array}{l}\text { Sektörel uzmanlaşma ve yeni- } \\
\text { likçi uzmanlaşma arasında bir } \\
\text { ilişki olduğu vurgulanmaktadır. }\end{array}$ \\
\hline $\begin{array}{l}\text { Özcan } \\
\text { ve Tuncer } \\
(2015)\end{array}$ & $\begin{array}{l}\text { Bölgesel } \\
\text { Çeşitlendirme }\end{array}$ & $\begin{array}{l}\text { Herfindahl- } \\
\text { Hirschman ve } \\
\text { Duranton-Puga } \\
\text { Endeksleri }\end{array}$ & $2004-2011$ & $\begin{array}{l}\text { Analiz sonuçları bölgesel çeşitli- } \\
\text { liğin en yüksek olduğu ilin } \\
\text { Bursa olduğunu ortaya koy- } \\
\text { maktadır. }\end{array}$ \\
\hline $\begin{array}{l}\text { Pan ve } \\
\text { Tsai (2012) }\end{array}$ & $\begin{array}{l}\text { Bölgesel } \\
\text { Çeşitlendirme }\end{array}$ & $\begin{array}{l}\text { Regresyon Ana- } \\
\text { lizi }\end{array}$ & $2002-2005$ & $\begin{array}{l}\text { Firma performansı üzerinde, } \\
\text { bölgesel çeşitliliğin önemli ve } \\
\text { belirleyici rol oynadığı vurgu- } \\
\text { lanmaktadır. }\end{array}$ \\
\hline $\begin{array}{l}\text { Çınar ve } \\
\text { Göksel (2010) }\end{array}$ & $\begin{array}{l}\text { Bölgesel } \\
\text { Çeşitlendirme }\end{array}$ & Entropi Yöntemi & $2002-2009$ & $\begin{array}{l}\text { İmalat sanayi ihracatı artarken } \\
\text { çeşitlendirmenin arttı̆ }{ }_{1} \text { ifade } \\
\text { edilmektedir. }\end{array}$ \\
\hline $\begin{array}{l}\text { Gündem ve } \\
\text { Acar } \\
(2011)\end{array}$ & Uzmanlaşma & $\begin{array}{l}\text { Yerelleşme } \\
\text { Katsayısı Tekniği } \\
\text { (LQ) ve } \\
\text { Hirschmann- } \\
\text { Herfindahl } \\
\text { İndeksi (HH) }\end{array}$ & 2003-2008 & $\begin{array}{l}\text { Uzmanlaşma düzeyinin yüksek } \\
\text { olduğu sektörlerde piyasa yo- } \\
\text { ğunlaşması söz konusudur. }\end{array}$ \\
\hline $\begin{array}{l}\text { Qian vd. } \\
(2008)\end{array}$ & $\begin{array}{l}\text { Bölgesel } \\
\text { Çeşitlendirme }\end{array}$ & $\begin{array}{l}\text { Panel Veri } \\
\text { Analizi }\end{array}$ & $1996-2000$ & $\begin{array}{l}\text { Bölgesel çeşitlendirmenin firma } \\
\text { performansını belirli bir eşiğe } \\
\text { kadar doğrusal olarak artırdığı } \\
\text { daha sonra etkisinin negatif ol- } \\
\text { duğu saptanmıştır. }\end{array}$ \\
\hline
\end{tabular}

Çınar ve Göksel (2010) tarafından yapılan çalışmada, dış satımda bölgesel çeşitlendirme ile istikrar konusu Türkiye verilerinden faydalanılarak ihracattaki büyüme (2002-2008) ve kriz (2009) dönemleri için analiz edilmektedir. Entropi yönteminin kullanıldığı bu araştırmada; 2002-2009 döneminde çeşitlendirmenin imalat sanayi ihracatı artarken arttı̆̆ı, kriz öncesinde nispeten istikrarlı olan sektörlerin krizden ihracat bakımından daha az etkilenen sektörler olduğu ve pazarlarını daha fazla çeşitlendirmiş olan sektörlerin ihracat açısından daha istikrarlı oldukları vurgulanmaktadır. 
Gündem ve Acar (2011) tarafından yapılan çalışmada, Türkiye'de imalat sanayi sektöründe istihdam ve yerel birim sayısı verileri kullanılarak bölgesel uzmanlaşma, yoğunlaşma ve çeşitlenme düzeyleri tespit edilmektedir. 2005 yilı haricinde 2003-2008 döneminin ele alındığı bu araştırma sonucunda; uzmanlaşma düzeyinin yüksek olduğu sektörlerde piyasa yoğunlaşmasının söz konusu olduğu, genellikle en yüksek bölgesel uzmanlaşmanın düşük teknolojili sektörler üzerinde yoğunlaşma gösterdiği ifade edilmektedir.

Pan ve Tsai (2012)'e ait 2002-2005 dönemi için bölgesel çeşitlilik ve firma performansı konularının incelendiği araştırma kapsamında, Tayvan veri bankasından yararlanılarak firma düzeyindeki panel veriler ile regresyon analizi yapılmaktadır. Çalışma sonucunda, bölgesel çeşitliliğin firma performansı üzerinde önemli ve belirleyici rol oynadığını vurgulanmaktadır.

Özcan ve Tuncer (2015) tarafından yapılan çalışmada, Türkiye'deki fonksiyonel kamu harcamalarının mekânsal yoğunlaşmasını ve bölgesel çeşitliliğini analiz etmek amaçlanmaktadır. 2004 ve 2011 dönemi için Herfindahl-Hirschman ve Duranton-Puga endekslerinden faydalanılarak yapılan analiz sonuçları; bölgesel çeşitlilik açısından en yüksek düzeye sahip ilin Bursa olduğunu ortaya koymaktadır. Ayrıca çalışmada, hükümetin ilgili dönem süresince harcama bakımından konut ve sosyal yardım hizmetleri üzerinde mekânsal yoğunlaşma gerçekleştirdiğinden bahsedilmektedir.

Broekel ve Mewes (2017), yaptıkları çalışmada Alman işgücü piyasası bölgelerinde Ar-Ge politikası ile bölgesel teknolojik çeşitlilik arasındaki ilişkiyi 1996-2010 dönemi için ele almaktadırlar. Panel veri kümesine dayanan çalışma bulgularında Almanya'daki Ar-Ge politikasının bölgesel teknolojik çeşitliliği desteklemediği ve etkilemediği saptanmıştır.

Gömleksiz ve Mercan (2017)'a ait araştırmada, bölgesel ekonomik büyümeye endüstriyel yoğunlaşma ve uzmanlaşmanın etkileri Türkiye imalat sanayi için incelenmekte olup 2006-2014 dönemi ve 26 Düzey 2 bölgesi ele alınmaktadır. Araştırma bulguları, bölgesel ekonomik büyüme üzerinde uzmanlaşma ve endüstriyel yoğunlaşmaya ilişkin dışsallıkların önemli belirleyiciler olduğunu ortaya koymaktadır.

Şahin ve Altuğ (2017)'a ait çalışmada, İstanbul, Ankara ve İzmir bölgelerinin imalat sanayinde hangi sektörlerde uzmanlaştı̆ının saptanması amaçlanmakta ve üç bölgenin yenilikçi uzmanlaşma endeksi (YUK) kullanılarak imalat sanayi alt sektörlerinin patent başvuruları 2007 ve 2016 yılları için analiz edilmektedir. Analiz bulgularında imalat sanayi alt sektörleri açısından sektörel uzmanlaşma ve yenilikçi uzmanlaşma arasında bir ilişki olduğu vurgulanmaktadır. 
Çiftçi (2018) tarafından yapılan çalışmada, lokasyon yani yerelleşme katsayısı yaklaşımı kullanılarak akademisyen istihdamının Türkiye'de il bazlı (düzey 3) dağılımları dikkate alınarak bölgesel uzmanlaşma düzeyleri ve akademik rotasyon durumu analiz edilmektedir. Akademik ünvana bakılarak ve bakılmaksızın iki farklı yaklaşım kullanılarak bölgesel uzmanlaşma düzeyleri akademik istihdam açısından değerlendirilmektedir.

Şahin, Yılmaz ve Varol (2018)'un yaptıkları araştırmada, bilgi yoğun iş hizmetlerinin bölgesel kalkınmadaki rolü bölgesel uzmanlaşma bağlamında detaylı sektör verileri yardımıyla incelenmektedir. Türkiye'de 2009 ve 2015 yılları ve 26 adet Düzey-2 bölgesi için yerelleşme katsayı tekniğinin kullanıldığı bu çalışma sonucunda telekomünikasyon sektörü haricindeki tüm bilgi yoğun iş hizmetleri sektörlerinin uzmanlaşma alanlarının büyük şehirler olduğu belirtilmektedir.

Askarany ve Spraakman (2020) tarafından yapılan araştırmada, bölgesel çeşitlendirme ve bir firmanın finansal performansı arasındaki ilişki aşırı kapasite teorisi objektifinden incelenmekte ve 1997-2017 yılları için Yeni Zelanda'da bir firma ele alınmaktadır. Çalışma kapsamında derinlemesine vaka çalışması yapılmakta olup araştırma sonucunda; yeni ürünlerin katkı marjı (çeşitlendirme sonucunda) feda edilenlerden daha yüksekse (düşükse), çeşitlendirmenin daha yüksek (düşük) finansal performansa yol açacağı, böylece firmaların çeşitlendirme ve finansal performansları arasında pozitif (negatif) bir ilişki görüleceği, eşit olduğu durumda değişiklik olmayacağı belirtilmektedir.

Tsai, Ren ve Eisingerich (2020)'e ait çalışmada, Çin'deki firma performansı üzerine bölge içi ve bölgeler arası coğrafi çeşitlendirme stratejilerinin etkileri 2005-2014 dönemi için panel regresyon tahminleri ile araştırılmaktadır. Tahmin bulgularına bölgesel çeşitliliğin firma performansı üzerinde önemli bir etkisi bulunmaktadır.

Qian vd. (2008) tarafına ait çalışmada, bölgesel çeşitliliğin firma performansını 1996-2000 dönemi için nasıl etkilediği panel veri analiz yöntemiyle araştrılmakta olup çalışma sonucunda bölgesel çeşitliliğin firma performansını belirli bir eşiğe kadar doğrusal olarak artırdığı, daha sonra etkisinin negatif olduğu saptanmıştır. Ayrıca araştırmada gelişmiş ülke firmalarının, sınırlı sayıda gelişmiş/gelişmekte olan bölgede faaliyet gösterdiklerinde performanslarını en üst düzeye çkardıkları belirtilmektedir.

Literatürde yer alan çalışmalara bakıldığında bölgesel çeşitlilik, uzmanlaşma ve yoğunlaşma konuları gerek il veya bölge gerekse ülke bazında çeşitli göstergelerle incelenmektedir. Bu çalışmalar arasında uzmanlaşma, yoğunlaşma ve çeşitlenme düzeylerini bilgi yoğun iş hizmetleri (bkz. Şahin, Yılmaz 
ve Varol, 2018), Ar-Ge politikası (bkz. Broekel ve Mewes, 2017) gibi parametrelerle ele alan araştırmalar bulunmakla birlikte bölgesel çeşitlilik ya da çeşitlendirme ile firma performansı ilişkisini ele alan araştırmalar da (Ör: Askarany ve Spraakman, 2020; Pan ve Tsai, 2012; Tsai, Ren ve Eisingerich, 2020; Qian vd., 2008) mevcuttur. Bölgesel çeşitlilik, uzmanlaşma ve yoğunlaşma konuları aynı zamanda sektörel açıdan da incelenmektedir (Ör: Gömleksiz ve Mercan, 2017; Gündem ve Acar, 2011; Şahin ve Altuğ, 2017; Şahin, Yılmaz ve Varol, 2018). Bu bağlamda yazında imalat sanayi sektörü için de bölgesel çeşitlilik, uzmanlaşma ve yoğunlaşma konuları incelenmektedir. Bu kapsama giren çalışmalar: Gömleksiz ve Mercan, (2017); Gündem ve Acar, (2011) ve Şahin ve Altuğ, (2017) iken bu araştırmalardan Gündem ve Acar, (2011)'a ait çalışmada istihdam verisi kullanılmaktadır.

Bu çalışmada ise yazındaki diğer çalışmalardan farklı olarak Türkiye'de illerin imalat sanayi sektöründe istihdamının çeşitlilik/uzmanlaşma düzeyleri ele alınmakta olup Gündem ve Acar (2011)'a ait çalışmadan farklı olarak Duranton-Puga endeksi kullanılmaktadır. Çalışma ile güncel verilerden yararlanılarak Türkiye'de illerin imalat sanayi sektöründe çeşitlilik/uzmanlaşma düzeyleri tespit edilmekte ve sektörel çeşitlilik/uzmanlaşma değerleri kullanılarak illerin sıralaması yapılmaktadır.

\section{Yöntem ve Veri Seti}

Literatürde çeşitlilik/uzmanlaşma düzeylerini ölçmek için farklı yöntemler kullanılmaktadır. En yaygın kullanılan üç yöntem; ulusal ortalama, kümülatif dağılım (Ogive) ve dayanıklı tüketim mallarında istihdamın yüzdesi göstergesidir (Jackson, 1984, s.104). Conroy (1975) tarafından yapılan çalışmada, söz konusu üç yöntem ve kullanılan göstergeler özetlenmektedir. Söz konusu üç ana yönteme ek olarak, literatürde ekonomik faaliyetlerin belli bir zamanda ve belli bir mekanda uzmanlaşma ve çeşitliliğinin ölçülmesinde kullanılan Maksimum Oran Endeksi, Herfindahl Endeksi, Simpson Endeksi, Entropi Endeksi, Değiştirilmiş (Modified) Entropi Endeksi ve Karma (Composite) Entropi Endeksi, Hausmann Çeşitlilik Endeksi, Krugman Benzersizlik (Dissimilarity) Endeksi gibi değişkenler de kullanılmaktadır (Babu ve Gulati, 2005, s. 261; Goschin vd., 2009, s.104; TEPAV, 2016, s.45-46.).

Bu çalışmada Türkiye'de illerin imalat sanayi sektöründe istihdamının çeşitlilik/uzmanlaşma düzeylerini tespit etmek amaçlanmış ve bu amaçla 2019 yılı ve 81 il için Duranton-Puga Endeks değerleri hesaplanmıştır. Çalışmada veri seti olarak 2019 yılına ait TÜIK (2021) il düzeyinde imalat sanayi alt sektörlerine göre istihdam verileri kullanılmıştır. 
Duranton ve Puga (2000), kentsel uzmanlık ve çeşitliliğin avantajları ile dezavantajlarını incelemiş ve göreceli çeşitlilik endeksini her bir sektörün yerel istihdamdaki payı ile ulusal istihdamdaki payı arasındaki farkın mutlak değerini tüm sektörlerdeki her şehir için toplayarak hesaplamıştır. İlgili hesaplama yöntemi şu şekildedir (Duranton ve Puga, 2000):

$$
R D I_{i}=1 / \sum_{j}\left|S_{i j}-S_{j}\right|
$$

Denklemde RDI $i$ bölgesindeki göreli çeşitlilik endeksini, $S_{i j} i$ bölgesindeki endüstri $j^{\prime}$ nin payını, $S_{j}$ ulusal ekonomideki endüstri $j$ 'nin payını temsil etmektedir.

Bu çalışmada istihdamın çeşitlilik/uzmanlaşma düzeylerinin tespiti için aşağıdaki denklemin hesaplaması yapılmıştır. Denklemin oluşturulmasında Özcan ve Tuncer (2015) çalışmasından yararlanılmıştır (Özcan ve Tuncer, 2015, s.189):

$$
D P_{t}=1 / \sum_{i=1}^{n}\left|\frac{F \dot{\mathrm{I}}_{i t}}{F \dot{\mathrm{I}}_{t}}-\frac{F \dot{\mathrm{I}}_{i n}}{F \dot{\mathrm{I}}_{n}}\right|
$$

$D P_{t} \mathrm{t}$ ilindeki Duranton-Puga Endeksi değerini, $F \mathrm{I}_{i t} \mathrm{t}$ ili i fonksiyonu için istihdam sayısın, $F \dot{\mathrm{I}}_{t}$ tilindeki toplam istihdam sayısını, $F \dot{\mathrm{I}}_{\text {in }}$ n ülkesi (Türkiye) i fonksiyonu için istihdam sayısını, $F \dot{I}_{n} n$ ülkesindeki (Türkiye) toplam istihdam sayısını ifade etmektedir.

\section{Bulgular}

Illere göre istihdam verileri kullanılarak sektörel çeşitlilik ve uzmanlaşma düzeylerinin hesaplandığı Duranton-Puga Endeksi sonuçları Tablo 2'de sunulmaktadır.

\begin{tabular}{|c|c|c|c|c|c|c|c|c|}
\hline No & ìl & Değer & No & il & Değer & No & ìl & Değer \\
\hline 1 & İzmir & 3,758 & 28 & Şanliurfa & 1,206 & 55 & Yalova & 0,915 \\
\hline 2 & İstanbul & 2,591 & 29 & Trabzon & 1,191 & 56 & Uşak & 0,906 \\
\hline 3 & Adana & 2,471 & 30 & Nevşehir & 1,188 & 57 & Adiyaman & 0,905 \\
\hline 4 & Samsun & 2,277 & 31 & Sivas & 1,186 & 58 & Mardin & 0,904 \\
\hline 5 & Tekirdağ & 2,171 & 32 & Niğde & 1,164 & 59 & Ordu & 0,903 \\
\hline 6 & Sakarya & 2,102 & 33 & Hatay & 1,144 & 60 & Çanakkale & 0,899 \\
\hline 7 & Mersin & 1,844 & 34 & Bilecik & 1,138 & 61 & Giresun & 0,886 \\
\hline 8 & Düzce & 1,839 & 35 & Kütahya & 1,129 & 62 & Tokat & 0,879 \\
\hline 9 & Konya & 1,822 & 36 & Isparta & 1,128 & 63 & Batman & 0,839 \\
\hline 10 & Diyarbakır & 1,792 & 37 & Bartın & 1,124 & 64 & Muğla & 0,836 \\
\hline 11 & Bursa & 1,772 & 38 & Iğdır & 1,090 & 65 & Van & 0,788 \\
\hline
\end{tabular}

Tablo 2. Duranton-Puga Endeksi Sonuçları 


\begin{tabular}{|c|c|c|c|c|c|c|c|c|}
\hline 12 & Eskişehir & 1,635 & 39 & Elâzı̆̆ & 1,057 & 66 & Erzurum & 0,786 \\
\hline 13 & Antalya & 1,535 & 40 & Malatya & 1,040 & 67 & Tunceli & 0,785 \\
\hline 14 & Kocaeli & 1,522 & 41 & Denizli & 1,027 & 68 & Karabük & 0,752 \\
\hline 15 & Manisa & 1,497 & 41 & Kilis & 1,017 & 69 & Kars & 0,735 \\
\hline 16 & Ankara & 1,496 & 43 & Osmaniye & 1,016 & 70 & Bingöl & 0,730 \\
\hline 17 & Kayseri & 1,475 & 44 & Gaziantep & 1,009 & 71 & Ağr1 & 0,711 \\
\hline 18 & Aydın & 1,384 & 45 & Şırnak & 1,002 & 72 & Karaman & 0,708 \\
\hline 19 & Çankırı & 1,370 & 46 & Afyonkarahisar & 0,989 & 73 & Muş & 0,707 \\
\hline 20 & Çorum & 1,368 & 47 & Erzincan & 0,972 & 74 & Gümüşhane & 0,689 \\
\hline 21 & Amasya & 1,366 & 48 & Kastamonu & 0,956 & 75 & Rize & 0,682 \\
\hline 22 & Aksaray & 1,341 & 49 & Kahramanmaraş & 0,954 & 76 & Ardahan & 0,655 \\
\hline 23 & Yozgat & 1,324 & 50 & Kırıkkale & 0,946 & 77 & Hakkâri & 0,650 \\
\hline 24 & Balıkesir & 1,321 & 51 & Edirne & 0,941 & 78 & Artvin & 0,649 \\
\hline 25 & Bolu & 1,285 & 52 & Kurşehir & 0,933 & 79 & Siirt & 0,631 \\
\hline 26 & Kırklareli & 1,277 & 53 & Burdur & 0,931 & 80 & Bitlis & 0,625 \\
\hline 27 & Sinop & 1,264 & 54 & Zonguldak & 0,921 & 81 & Bayburt & 0,583 \\
\hline
\end{tabular}

Duranton-Puga Endeks sonuçları 81 il için 0,58 ile 3,76 arasında değişkenlik göstermektedir. İmalat sanayi sektöründe İzmir, İstanbul, Adana, Samsun, Tekirdağ gibi illerde endeks değerinin yüksek olduğu saptanmıştır. Bu illerin endeks değerinin yüksek olması istihdamın çok farklı sanayi kollarına dağıldığının bir göstergesidir. Benzer şekilde; Sakarya, Mersin, Düzce, Konya, Diyarbakır, Bursa ve Kocaeli illerinde de istihdamın yer aldığı sanayi kolları oldukça fazladır. Aksine endeks değerinin düşük olması ise sektörel çeşitliliğin olmadığı, istihdamın birkaç sektörde yoğunlaştığı anlamına gelmektedir. Bu bakımdan; endeks değerinde son sıralarda yer alan Hakkâri, Artvin, Siirt, Bitlis, Bayburt gibi illerde ise istihdam açısından sektörel çeşitlilik bulunmamaktadır. Diğer bir ifade ile endeks değerinin düşük olduğu illerde istihdam bütün sanayi kollarına dağılmamakta, belirli sektörlerde (illere göre değişken) yer almaktadır. Yine bu illerde olduğu gibi Karabük, Kars, Bingöl, Ağrı, Karaman, Muş, Gümüşhane, Rize ve Ardahan illeri de oldukça düşük endeks değerine sahip iller arasında yer almaktadır. Endeks sonuçları Şekil 1'de görselleştirilmiştir.

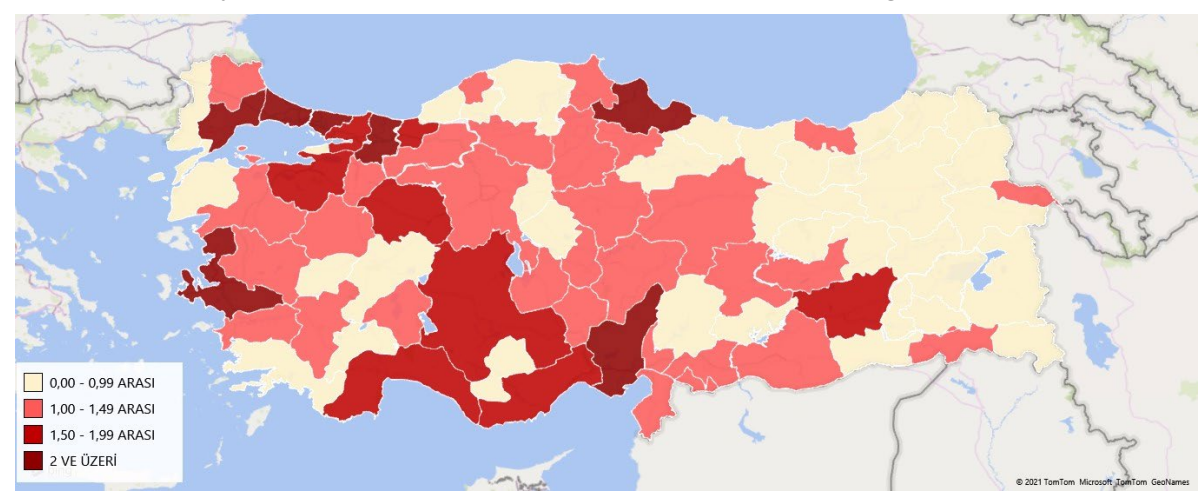

Şekil 1. Duranton-Puga Endeksi Sonuçları 
Duranton-Puga endeksi sonuçları, illerin 2019 yılı için kişi başı Gayrisafi Yurt İçi Hasıla GSYİH (TL) değerleri (ilgili değerler için bkz. TUİK, 2021) ile kıyaslandığında endeks değeri yüksek olan illerin aynı zamanda kişi başı GSYİH değeri yüksek olan iller olduğu görülmektedir. Yani kişi başı GSYIH değeri yüksek illerin sektörel çeşitlilik katsayısı da yüksektir. Bu husus dikkate alınarak sektörel çeşitlilik ile büyüme ve gelişmenin birbiriyle bağlantılı değerler olduğu ifade edilebilir (bkz. Şekil 2).

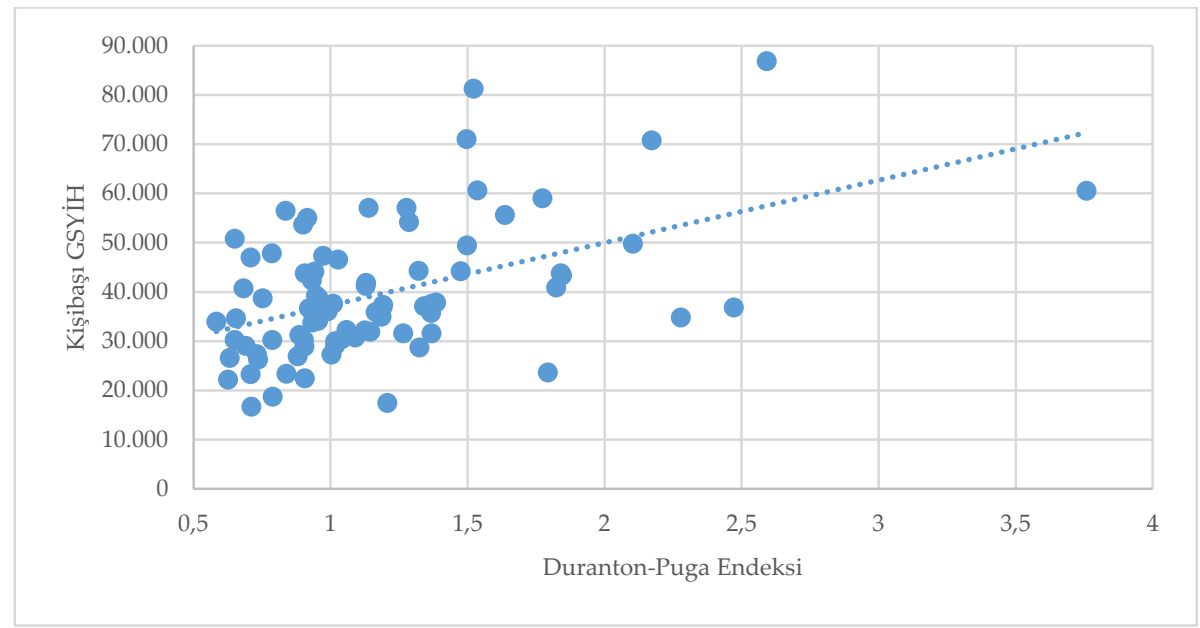

Şekil 2. Duranton-Puga Endeksi Sonuçları ve Kişi başı GSYIH

\section{Sonuç ve Değerlendirme}

Bölgelerin nasıl yeni büyüme yörüngeleri geliştirdiği ve bunu yapabilme yeteneği konusunda bölgelerin neden farklılaştı̆̆ı sorusu üzerine odaklanan güncel literatürde; yerel ilişkili faaliyetlerin mevcudiyetinin ana tetikleyici unsur olduğu belirtilmektedir. Boschma vd. (2016, s.2-3) tarafından yapılan çalışmada; ilişkili çeşitliliğin bölgelerde daha yaygin görülen bir olay olduğu, buna karşlık ilişkisiz çeşitliliğin ise daha nadiren ortaya çıan bir durum olduğu belirtilmektedir.

Ulusaltı bölgelerin ekonomik yapıları ve bu bölgelerin ulusal ekonomik faaliyetlerdeki dalgalanmalara verdikleri tepkiler arasındaki ilişki çok uzun bir zamandır bölgesel iktisat teorisinin ana konularından birisidir (Conroy, 1975, s.492). Bölgesel çeşitlilik ve bölgesel ekonomik istikrar (veya istikrarsızlık) konularına olan ilgi özellikle bazı bölgelerde ciddi ekonomik sorunlar ortaya çıtığında daha da artmaktadır (Brewer, 1985, s.463). Ne var ki, bölgesel endüstriyel çeşitliliğin nasıl ölçüleceği konusunda bir tartşma süregelmektedir. Bölgesel endüstriyel çeşitlilik, farklı şekillerde tanımlanabilmekte ve ölçülebilmekte- 
dir. Bu çalışmada, bu yöntemlerden birisi olan Duranton-Puga Endeksi kullanılmış ve Türkiye'de il düzeyinde imalat sanayi sektörü itibariyle illerin sektörel uzmanlaşma-çeşitlilik düzeyleri hesaplanmıştır.

Bölgelerin endüstriyel uzmanlaşma veya çeşitlilik düzeylerinin tespit edilmesi; bölgelere özgü politikalar oluşturulması, bölgesel rekabetçilik açısından güçlü yönlerin-fırsatların belirlenmesi, ekonomik krizler karşısında uygulanacak politikaların tespit edilmesi gibi konular açısından oldukça büyük önem arz etmektedir.

Çalışmada elde edilen sonuçlar; İzmir, İstanbul, Adana, Tekirdağ, Sakarya, Mersin, Düzce, Konya, Bursa, Antalya, Kocaeli, Manisa, Ankara, Aydın gibi sanayileşmiş illerde sektörel çeşitlilik katsayısının yüksek olduğunu, dolayısıyla bu illerde istihdamın çok farklı imalat sanayi kollarına dağıldığını göstermektedir. Buna karşın; büyük çoğunluğu Doğu ve Güneydoğu bölgelerinde yer alan illerde ise imalat sanayi sektörlerinde çeşitliliğin olmadığı, bu illerde daha çok "sektörel çeşitsizlik" olduğu sonucu ortaya çımaktadır. 


\section{Extended Abstract}

\section{Regional Diversity or Specialization? Ranking of Provinces According to Diversity/Specialization Levels in Manufacturing Industry}

\author{
Onur Sungur \\ ORCID: 0000-0001-6778-4370
}

*

\author{
Habibe Yaman \\ ORCID: 0000-0002-9212-3264
}

Differences in regions' innovation-growth processes and the reasons behind regional diversification/specialization have recently been on the agenda of scientists and policy makers. In this regard, there are two important main concepts in the Regional Science literature that have gained increasing interest in recent years. One of these is "regional specialization", while the other is the concept of "regional diversification". Both concepts have various implications for innovativeness, competition, growth performance or the ability of regions to respond to crises-recessions.

Many elements, such as globalization and knowledge, have an impact on the level of specialization and diversity of Regions. With the globalized economic process, the differences between regions and provinces are increasing. This element, which cannot be ignored from the point of view of economic development, also highlights issues such as diversity, specialization and concentration under the influence of the knowledge-based process. The contributions of these concepts to regional and urban economic growth are innovation, efficiency, technology, etc. in many respects it is often mentioned in the literature. In addition, the level of sectoral expertise or diversity affects foreign trade performance and resilience to national/global economic shocks. For example, if the sectoral diversity of the province is low, it is likely that a decline in demand in the sectors where the share of exports is high will negatively affect the economy of the province. The negligence of a province that meets the majority of its exports from a few sectors to experience a decrease in production, employment and exports in the face of negative global developments in these sectors is quite high. Sectoral diversity is important not only in terms of exports, but also in 
terms of the stable growth of the province, increasing the development potential of new sectors and ensuring regional economic stability. In this context, in order to reduce the risks that may arise from the lack of sectoral diversity, the necessity of implementing sectoral diversification policies of provinces/regions with little sectoral diversity stands out.

There are many studies on regional diversity and specialization. The basis of models and empirical studies focusing on regional specialization and industrial concentration is mainly based on 19th-20th century trade theory and location theory. Regional specialization expresses the regional perspective and shows the distribution of sectoral shares in the overall economy of the region compared to the rest of the country. The fact that a small number of industries have a large combined share in the economy of that region means that the region is highly specialized (Goschin et al., 2009, p.100). In a study conducted by TEPAV (2016, p.44), it is stated that the sectoral diversification needs of the provinces differ according to the development levels of the provinces and it is thought that sectoral specialization rather than sectoral diversity will be appropriate for provinces that exceed a certain level of development. Therefore, determining the level of industrial specialization or diversity of Regions is important for issues such as creating regional policies, determining strengths-opportunities in terms of regional competitiveness, and identifying policies that will be applied in the face of economic crises. Especially in case of serious economic problems in some regions, the interest in these issues increases.

Research involving regional diversity and specialization in literature includes different fields and topics. There is no general opinion in terms of regional diversity and specialization in these studies where various methods are applied. There is ongoing debate on how to measure regional industrial diversity, and regional industrial diversity can be defined and measured in different ways.

The purpose of this study; is to determine the variety/specialization level of provinces in manufacturing industry in Turkey. In this context; relative diversity/concentration index (Duranton-Puga Index) of the provinces is calculated by using the employment data by provinces by the year of 2019. Employment data according to provincial level manufacturing industry sub-sectors are used as data set in the study. Next, by using sectoral diversity/specialization value of the provinces, the ranking of the provinces is established in the manufacturing sector. Duranton-Puga Index results vary between 0.58 and 3.76 for 81 provinces. In the manufacturing industry sector, it was found that the index value was high in provinces such as Izmir, Istanbul, Adana, Samsun, Tekirdag, and in these provinces, employment was distributed in different industrial 
branches, and concentration was low. In other words, these provinces emerge as provinces with high sectoral diversity. Similarly; Sakarya, Mersin, Düzce, Konya, Diyarbakır, Bursa and Kocaeli provinces are also among the provinces with high sectoral diversity. In provinces such as Hakkâri, Artvin, Siirt, Bitlis, Bayburt, which rank last in the index value, it has been found that employment is concentrated in certain sectors where there is not much diversification in sectors. Accordingly, there is no sectoral diversity in these provinces, there is sectoral specialization (or concentration of employment in one sector). As in these provinces, Karabük, Kars, Bingöl, Ağrı, Karaman, Muş, Gümüşhane, Rize and Ardahan provinces are among the provinces with very low index value and low sectoral diversity.

In summary, the results obtained in the study; it shows that the coefficient of sectoral diversity is high in industrialized provinces such as Izmir, Istanbul, Adana, Tekirdağ, Sakarya, Mersin, Düzce, Konya, Bursa, Antalya, Kocaeli, Manisa, Ankara, Aydın, and therefore the manufacturing industry sectors in the provinces are quite diverse instead of concentrating in a single sector. However, the result is that there is no diversity in the manufacturing industry sectors in provinces, most of which are located in the Eastern and Southeastern regions.

\section{Kaynakça/References}

Aiginger, K. ve Rossi-Hansberg, E. (2006). Specialisation and concentration: a note on theory and evidence. Empirica, 33, 255-266.

Askarany, D. ve Spraakman, G. (2020). Regional diversification and financial performance through an excess-capacity theory lens: A new explanation for mixed results. Technological Forecasting and Social Change, 156, 120076.

Babu, S. C. ve Gulati, A. (2005). Economic reforms and food security: the impact of trade and technology in South Asia. New York: Food Products Press.

Binz, C., Truffer, B. ve Coenen, L. (2016). Path creation as a process of resource alignment and anchoring-industry formation for on-site water recycling in Beijing. Economic Geography, 92 (2), 172-200.

Boschma, R. A. ve Frenken K. (2006). Why is economic geography not an evolutionary science? Towards an evolutionary economic geography. Journal of Economic Geography 6 (3), 273-302.

Boschma, R. ve Capone, G. (2015). Institutions and diversification: related versus unrelated diversification in a varieties of capitalism framework. Research Policy 44, 1902-1914.

Boschma, R. ve Frenken, K. (2011). Technological relatedness and regional branching.In: Bathelt, H., Feldman, M.P. ve Kogler, D. F. (eds.), Beyond Territory. Dynamic Geographies of Knowledge Creation, Diffusion and Innovation, Routledge, London and New York, 6481. 
Boschma, R., Balland, P. A. ve Kogler, D. F. (2015). Relatedness and technological change in cities: the rise and fall of technological knowledge in US metropolitan areas from 1981 to 2010. Industrial and Corporate Change, 24 (1), 223-250.

Boschma, R., Coenen, L., Frenken, K., ve Truffer, B. (2016). Towards a theory of regional diversification. Papers in Evolutionary Economic Geography, 16, 17.

Boschma, R., G. Heimeriks ve Balland, P. A. (2014). Scientific knowledge dynamics and relatedness in biotech cities. Research Policy 43 (1), 107-114.

Brewer, H. L. (1985). Measures of diversification: predictors of regional economic instability. Journal of Regional Science, 25(3), 463-470.

Broekel, T. ve Mewes, L. (2017). Analyzing the impact of R\&D policy on regional diversification. Papers in Evolutionary Economic Geography 17.26. Utrecht University, Section of Economic Geography.

Castaldi, C., Frenken, K. ve Los, B. (2015). Related variety, unrelated variety and technological breakthroughs: an analysis of US state-level patenting. Regional Studies, 49 (5), 767-781.

Conroy, M. E. (1975). The concept and measurement of regional industrial diversification. Southern Economic Journal, 41(3), 492-505.

Crespo, J., Suire R. ve Vicente J. (2014). Lock-in or lock-out? How structural properties of knowledge networks affect regional resilience. Journal of Economic Geography, 14(1), 199219.

Çınar, Y. ve Göksel, T. (2010). İhracatta bölgesel çeşitlendirme ve istikrar. Ankara Üniversitesi SBF Dergisi, 65(2).

Çiftçi, M. (2018). Türkiye'de akademik istihdamda bölgesel uzmanlaşma, akademik iş piyasası ve öğretim üyesi rotasyonu. EKEV Akademi Dergisi, 22(73), 233-262.

Duranton, G. ve Puga D. (2000). Diversity and specialisation in cities: why, where and when does it matter? Urban Studies, 37(3), 533-555.

Essleztbichler, J. (2015). Relatedness, industrial branching and technological cohesion in US metropolitan areas. Regional Studies 49(5), 752-766.

Ezcurra, R., Pascual, P. ve Rapun. M. (2006). Regional specialisation in the European Union. Regional Studies, 40(6), 601-616.

Filiztekin, A. (2008). Türkiye'de bölgesel farklar ve politikalar. TÜSİAD, Yayın No: TÜSİAD$\mathrm{T} / 2008-09 / 471$.

Frenken, K., Van Oort, F. G. ve Verburg, T. (2007). Related variety, unrelated variety and regional economic growth. Regional Studies, 41 (5), 685-697

Goschin, Z., Constantin, D.L., Roman, M. ve Ilenau, B. (2009). Regional specialisation and geographic concentration of industries in Romania. South-Eastern Europe Journal of Economics, 1, 99-113.

Gömleksiz, M. ve Mercan, B. (2017, 19-20 Mayıs). Endüstriyel yoğunlaşma ve uzmanlaşmanın bölgesel ekonomik büyüme üzerine etkisi: türkiye imalat sanayi üzerine bir inceleme. II. Uluslararası Sosyal Bilimler Sempozyumu, Alanya.

Gündem, F. ve Acar, S. (2011). Türkiye imalat sanayi'nde bölgesel uzmanlaşma (20032008). In Anadolu International Conference in Economics II. 
Hassink R. (2005). How to unlock regional economies from path dependency? From learning region to learning cluster. European Planning Studies, 13 (4), 521-535.

Hidalgo, C. A., Klinger, B., Barabási, A. L. ve Hausmann, R. (2007). The product space conditions the development of nations. Science, 317(5837), 482-487.

Jackson, R. W. (1984). An evaluation of alternative measures of regional industrial diversification. Regional Studies, 18(2), 103-112.

Ledebur, L. (1983). Planning for local and regional development. LMI Spectrum 2, 1-3.

Marelli, E. (2006). Specialisation and convergence of European regions. The European Journal of Comparative Economics, 2, 149-178.

Martın, R. (2010). Roepke lecture in economic geography - rethinking regional path dependence: beyond lock-in to evolution. Economic Geography 86 (1), 1-27.

Martin R. ve Sunley P. (2006). Path dependence and regional economic evolution. Journal of Economic Geography, 6(4), 395-437.

Neffke F., Henning M. ve Boschma, R. (2011). How do regions diversify over time? Industry relatedness and the development of new growth paths in regions. Economic $\mathrm{Ge}$ ography, 87(3), 237-265.

Neffke, F., Hartog, M., Boschma, R. ve Henning, M. (2014). Agents of structural change: the role of firms and entrepreneurs in regional diversification. Papers in Evolutionary Economic Geography 14.10, Utrecht University.

Özcan, S. E. ve Tuncer, G. (2015). Spatial concentration and regional diversification of public expenditures: the case of Turkey. Niğde Üniversitesi ÏIBF Dergisi, 8(1) 185-198.

Pan, W. H. ve Tsai, W. C. (2012). Internationalization, regional diversification and firm performance: the moderating effects of administrative intensity. International Journal of Business and Social Science, 3(18), 274-282.

Pascal, A. ve Gurwitz A. (1983). Picking winners: industrial strategies for local economic development. The Rand Corporation, R-2932-HUD.

Qian, G., Li, L., Li, J., ve Qian, Z. (2008). Regional diversification and firm performance. Journal of International Business Studies, 39(2), 197-214.

Rigby, D. (2015). Technological relatedness and knowledge space: entry and exit of US cities from patent classes. Regional Studies, 49 (11), 1922-1937.

Simmie, J. (2012). Path dependence and new path creation in renewable energy technologies. European Planning Studies, 20, 729-731.

Şahin, M. T. ve Altuğ, F. (2017). Türkiye'de yenilik faaliyetlerinde yenilikçi uzmanlaşma eğilimleri: İstanbul, Ankara ve İzmir bölgeleri imalat sanayi patent göstergeleri. Coğrafi Bilimler Dergisi, 15(2), 157-166.

Şahin, M. T., Yılmaz, M. ve Varol, Ç. (2018). Türkiye'de bilgi yoğun iş hizmetlerinin (BYİH) bölgesel uzmanlaşma örüntüsü. Ankara Üniversitesi Dil ve Tarih-Coğrafya Fakültesi Dergisi, 58(2), 1492-1521.

Tanner, A. N. (2014). Regional branching reconsidered: emergence of the fuel cell industry in European regions. Economic Geography, 90 (4), 403-427. 
Tanner, A. N. (2016). The emergence of new technology-based industries: the case of fuel cells and its technological relatedness to regional knowledge bases. Journal of Economic Geography, 16 (3), 611-635.

TEPAV (2016). Bölgesel rekabet gündemlerinin tasarımı için araç seti. Ankara: T.C. Kalkınma Bakanlığı GAP Bölge Kalkınma İdaresi Başkanlığı.

Tsai, H., Ren, S. ve Eisingerich, A. B. (2020). The effect of inter-and intra-regional geographic diversification strategies on firm performance in China. Management Decision, 58(1), $16-38$.

TUIK (2021). İ göstege. https://biruni.tuik.gov.tr/ilgosterge/?locale=tr (27.01.2021).

Wolman, H. (1979). Making local economic development decisions: a framework for local officials. Working Paper No. 1264-01, The Urban Institute, Washington, D.C. 